Article

\title{
Two Fixed Point Theorems Concerning F-Contraction in Complete Metric Spaces
}

\author{
Ovidiu Popescu *, ${ }^{\star}$ and Gabriel Stan ${ }^{\dagger}$
}

Department of Mathematics and Computer Science, Transilvania University of Brasov, 500036 Brasov, Romania; gabriel.stan@unitbv.ro

* Correspondence: ovidiu.popescu@unitbv.ro

† These authors contributed equally to this work.

Received: 26 November 2019; Accepted: 24 December 2019; Published: 27 December 2019

\begin{abstract}
In this paper, we generalize some results of Wardowski (Fixed Point Theory Appl. 2012:94, 2012), Cosentino and Vetro (Filomat 28:4, 2014), and Piri and Kumam (Fixed Point Theory Appl. 2014:210, 2014) theories by applying some weaker symmetrical conditions on the self map of a complete metric space and on the mapping $F$, concerning the contractions defined by Wardowski.
\end{abstract}

Keywords: banach principle; fixed point; metric space; F-contraction

\section{Introduction and Preliminaries}

Throughout this article, we denote by $\mathbb{N}$ the set of all natural numbers, by $\mathbb{R}$ the set of all real numbers, and by $\mathbb{R}_{+}$the set of all positive real numbers.

The Banach contraction principle [1] is the starting point in fixed point theory. This theorem has a lot of applications in many disciplines such as chemistry, physics, biology, computer science, and other branches of mathematics. Many authors improved, generalized and extended this classical result in nonlinear analysis. They defined new contractive mappings in the context of a complete metric space or investigated the existing contractive mappings in various abstract spaces, see e.g., [2-13] and references therein. In particular, in 1962, Edelstein [14] proved the following version of the Banach contraction principle.

Theorem 1 ([14]). Let $(X, d)$ be a compact metric space and let $T: X \rightarrow X$ be a self-mapping. Assume that $d(T x, T y)<d(x, y)$ holds for all $x, y \in X$ with $x \neq y$. Then $T$ has a unique fixed point in $X$.

Recently, in 2012, Wardowski [15] introduced a new type of contraction called F-contraction and generalized the Banach contraction principle.

Definition 1 ([15]). Let $(X, d)$ be a metric space. A mapping $T: X \rightarrow X$ is called an F-contraction if there exist $\tau>0$ and $F \in \mathcal{F}$ such that

$$
\tau+F(d(T x, T y)) \leq F(d(x, y))
$$

holds for any $x, y \in X$ with $d(T x, T y)>0$, where $\mathcal{F}$ is the set of all functions $F: \mathbb{R}_{+} \rightarrow \mathbb{R}$ satisfying the following conditions:

(F1) $\quad F$ is strictly increasing: $x<y \Rightarrow F(x)<F(y)$;

(F2) For each sequence $\left\{\alpha_{n}\right\}_{n \in \mathbb{N}}$ in $\mathbb{R}_{+}, \lim _{n \rightarrow \infty} \alpha_{n}=0$ if and only if

$$
\lim _{n \rightarrow \infty} F\left(\alpha_{n}\right)=-\infty ;
$$


(F3) There exists $k \in(0,1)$ such that $\lim _{\alpha \rightarrow 0_{+}} \alpha^{k} F(\alpha)=0$.

Remark 1. Obviously, if $T$ satisfies Inequality (1) and $F$ is an increasing function (not necessary strictly increasing), then $T$ is contractive, i.e.,

$$
d(T x, T y)<d(x, y), \forall x, y \in X, x \neq y
$$

so $T$ is continuous.

The following theorem is Wardowski's result:

Theorem 2 ([15]). Let $(X, d)$ be a complete metric space and let $T: X \rightarrow X$ an F-contraction. Then $T$ has a unique fixed point $x^{*} \in X$ and for every $x \in X$ the sequence $\left\{T^{n} x\right\}_{n \in \mathbb{N}}$ converges to $x^{*}$.

Secelean [16] showed that the condition (F2) in Definition 1 can be replaced by an equivalent condition,

$$
\inf F=-\infty
$$

or, also, by

(F2") there exists a sequence $\left\{\alpha_{n}\right\}_{n \in \mathbb{N}}$ of positive real numbers such that

$$
\lim _{n \rightarrow \infty} F\left(\alpha_{n}\right)=-\infty \text {. }
$$

He proved the following lemma:

Lemma 1 ([16]). Let $F: \mathbb{R}_{+} \rightarrow \mathbb{R}$ be an increasing mapping and $\left\{\alpha_{n}\right\}_{n \in \mathbb{N}}$ be a sequence of positive real numbers. Then the following assertions hold:

(i) if $\lim _{n \rightarrow \infty} F\left(\alpha_{n}\right)=-\infty$, then $\lim _{n \rightarrow \infty} \alpha_{n}=0$;

(ii) if inf $F=-\infty$, and $\lim _{n \rightarrow \infty} \alpha_{n}=0$, then $\lim _{n \rightarrow \infty} F\left(\alpha_{n}\right)=-\infty$.

Remark 2. Wardowski showed that if we take $F_{B}: \mathbb{R}_{+} \rightarrow \mathbb{R}, F_{B}(\alpha)=\ln \alpha$, then $F_{B} \in \mathcal{F}$, and the $F_{B}$-contraction reduces to a Banach contraction. Therefore, the Banach contractions are a particular case of F-contractions. Meanwhile there exist F-contractions which are not Banach contractions (see [15]).

Cosentino and Vetro [17] introduced the notion of F-contraction of Hardy-Rogers-type and generalized the result of Wardowski.

Definition 2 ([17]). Let $(X, d)$ be a metric space. A mapping $T: X \rightarrow X$ is called an F-contraction of Hardy-Rogers-type if there exist $\tau>0$ and $F \in \mathcal{F}$ such that

$$
\tau+F(d(T x, T y)) \leq F(\alpha \cdot d(x, y)+\beta \cdot d(x, T x)+\gamma \cdot d(y, T y)+\delta \cdot d(x, T y)+L \cdot d(y, T x))
$$

holds for any $x, y \in X$ with $d(T x, T y)>0$, where $\alpha, \beta, \gamma, \delta, L$ are non-negative numbers, $\gamma \neq 1$ and $\alpha+\beta+\gamma+2 \delta=1$.

Theorem 3 ([17]). Let $(X, d)$ be a complete metric space and let $T$ be a self-mapping on $X$. Assume that $T$ is an F-contraction of Hardy-Rogers-type, where $\gamma \neq 1$. Then Thas a fixed point. Moreover, if $\alpha+\delta+L \leq 1$, then the fixed point of $T$ is unique. 
Very recently, Piri and Kumam [18] introduced the following condition instead of the condition (F3) in Definition 1:

(F3') $\quad F$ is continuous on $(0, \infty)$.

They denoted by $\mathfrak{F}$ the set of all functions satisfying the conditions $(F 1),\left(F 2^{\prime}\right)$ and $\left(F 3^{\prime}\right)$ and proved the following generalization of the Banach contraction principle:

Theorem 4 ([18]). Let $T$ be a self-mapping of a complete metric space $X$ into itself. Suppose $F \in \mathfrak{F}$ and there exists $\tau>0$ such that

$$
\forall x, y \in X,[d(T x, T y)>0 \Rightarrow \tau+F(d(T x, T y)) \leq F(d(x, y))] .
$$

Then $T$ has a unique fixed point $x^{*} \in X$ and for every $x \in X$ the sequence $\left\{T^{n} x\right\}_{n \in \mathbb{N}}$ converges to $x^{*}$.

Remark 3. Piri and Kumam showed that $(F 3)$ and $\left(F 3^{\prime}\right)$ are independent of each other, i.e., $\mathcal{F} \backslash \mathfrak{F} \neq \varnothing$, $\mathfrak{F} \backslash \mathcal{F} \neq \varnothing$ and $\mathcal{F} \cap \mathfrak{F} \neq \varnothing$. More precisely, for $F(\alpha)=-1 / \alpha^{p}, p \geq 1$, we have $F \in \mathfrak{F}, F \notin \mathcal{F}$, and for $F(\alpha)=-1 /(\alpha+[\alpha])^{t}, t \in(0, c), c<1$, we have $F \in \mathcal{F}$ and $F \notin \mathfrak{F}$. Also, for $F(\alpha)=\ln \alpha$, we have $F \in \mathcal{F} \cap \mathfrak{F}$.

The reader interested in fixed points results obtained employing the concept of $F$-contraction is referred to [19-31]. In this paper, we proved that some of the conditions in Theorems 2-4 are superfluous.

\section{Main Results}

The following theorem is a partial generalization of Theorem 3 and a generalization of Theorem 2.

Theorem 5. Let $T$ be a selfmapping of a complete metric space $X$ into itself. Suppose there exists $\tau>0$ such that for all $x, y \in X, d(T x, T y)>0 \Rightarrow$

$$
\begin{aligned}
& \tau+F(d(T x, T y)) \\
\leq \quad & F(\alpha \cdot d(x, y)+\beta \cdot d(x, T x)+\gamma \cdot d(y, T y)+\delta \cdot d(x, T y)+L \cdot d(y, T x)),
\end{aligned}
$$

where $F: \mathbb{R}_{+} \rightarrow \mathbb{R}$ is an increasing mapping, $\alpha, \beta, \gamma, \delta, L$ are non-negative numbers, $\delta<1 / 2, \gamma<1, \alpha+\beta+$ $\gamma+2 \delta=1,0<\alpha+\delta+L \leq 1$. Then $T$ has a unique fixed point $x^{*} \in X$ and for every $x \in X$ the sequence $\left\{T^{n} x\right\}_{n \in \mathbb{N}}$ converges to $x^{*}$.

Proof. Let $x_{0} \in X$ be an arbitrary point and construct a sequence $\left\{x_{n}\right\}_{n \in \mathbb{N}} \in X$ by

$$
x_{1}=T x_{0}, x_{2}=T x_{1}=T^{2} x_{0}, \ldots, x_{n}=T x_{n-1}=T^{n} x_{0}, \forall n \in \mathbb{N} .
$$

If there exists $n \in \mathbb{N} \cup 0$ such that $d\left(x_{n}, T x_{n}\right)=0$, then $x_{n}$ is a fixed point of $T$ and the proof is complete. Hence, we assume that

$$
0<d\left(x_{n}, T x_{n}\right)=d\left(T x_{n-1}, T x_{n}\right), \forall n \in \mathbb{N} .
$$


Now, let $d_{n}=d\left(x_{n}, x_{n+1}\right)$. By the hypothesis and the monotony of $F$, we have for all $n \in \mathbb{N}$

$$
\begin{aligned}
& \tau+F\left(d_{n}\right) \\
= & \tau+F\left(d\left(x_{n}, x_{n+1}\right)\right)=\tau+F\left(d\left(T x_{n-1}, T x_{n}\right)\right) \\
\leq & F\left(\alpha d\left(x_{n-1}, x_{n}\right)+\beta d\left(x_{n-1}, T x_{n-1}\right)+\gamma d\left(x_{n}, T x_{n}\right)+\delta d\left(x_{n-1}, T x_{n}\right)\right. \\
& \left.+L d\left(x_{n}, T x_{n-1}\right)\right) \\
= & F\left(\alpha d\left(x_{n-1}, x_{n}\right)+\beta d\left(x_{n-1}, x_{n}\right)+\gamma d\left(x_{n}, x_{n+1}\right)+\delta d\left(x_{n-1}, x_{n+1}\right)\right. \\
& \left.+L d\left(x_{n}, x_{n}\right)\right) \\
= & F\left(\alpha d_{n-1}+\beta d_{n-1}+\gamma d_{n}+\delta d\left(x_{n-1}, x_{n+1}\right)\right) \\
\leq & F\left(\alpha d_{n-1}+\beta d_{n-1}+\gamma d_{n}+\delta\left(d_{n-1}+d_{n}\right)\right) \\
= & \left.F\left((\alpha+\beta+\delta) d_{n-1}+(\gamma+\delta) d_{n}\right)\right) .
\end{aligned}
$$

It follows that

$$
\left.\left.F\left(d_{n}\right) \leq F\left((\alpha+\beta+\delta) d_{n-1}+(\gamma+\delta) d_{n}\right)\right)-\tau<F\left((\alpha+\beta+\delta) d_{n-1}+(\gamma+\delta) d_{n}\right)\right),
$$

so from the monotony of $F$, we get

$$
d_{n}<(\alpha+\beta+\delta) d_{n-1}+(\gamma+\delta) d_{n}
$$

and hence

$$
(1-\gamma-\delta) d_{n}<(\alpha+\beta+\delta) d_{n-1},
$$

for all $n \in \mathbb{N}$. Since $\gamma \neq 1$ and $\alpha+\beta+\gamma+2 \delta=1$, we deduce that $1-\gamma-\delta>0$ and so

$$
d_{n}<\frac{\alpha+\beta+\delta}{1-\gamma-\delta} d_{n-1}=d_{n-1}
$$

for all $n \in \mathbb{N}$. Thus, we conclude that the sequence $\left\{d_{n}\right\}_{n \in \mathbb{N}}$ is strictly decreasing, so there exists $\lim _{n \rightarrow \infty} d_{n}=d$. Suppose that $d>0$. Since $F$ is an increasing mapping there exists $\lim _{x \rightarrow d_{+}} F(x)=$ $F(d+0)$, so taking the limit as $n \rightarrow \infty$ in Inequality (5) we get $F(d+0) \leq F(d+0)-\tau$, which is a contradiction. Therefore,

$$
\lim _{n \rightarrow \infty} d_{n}=0 .
$$

Now, we claim that $\left\{x_{n}\right\}_{n \in \mathbb{N}}$ is a Cauchy sequence. Arguing by contradiction, we assume that there exist $\epsilon>0$ and sequences $\{p(n)\}_{n \in \mathbb{N}}$ and $\{q(n)\}_{n \in \mathbb{N}}$ of natural numbers such that $p(n)>q(n)>n$,

$$
d\left(x_{p(n)}, x_{q(n)}\right)>\epsilon, d\left(x_{p(n)-1}, x_{q(n)}\right) \leq \epsilon, \forall n \in \mathbb{N} .
$$

Then, we have

$$
\epsilon<d\left(x_{p(n)}, x_{q(n)}\right) \leq d\left(x_{p(n)}, x_{p(n)-1}\right)+d\left(x_{p(n)-1}, x_{q(n)}\right) \leq d\left(x_{p(n)-1}, x_{p(n)}\right)+\epsilon .
$$

It follows from Relation (6) and the above inequality that

$$
\lim _{n \rightarrow \infty} d\left(x_{p(n)}, x_{q(n)}\right)=\epsilon
$$


Since $d\left(x_{p(n)}, x_{q(n)}\right)>\epsilon>0$, by the hypothesis and the monotony of $F$, we have

$$
\begin{aligned}
& \tau+F\left(d\left(x_{p(n)}, x_{q(n)}\right)\right) \\
\leq & F\left(\alpha d\left(x_{p(n)-1}, x_{q(n)-1}\right)+\beta d\left(x_{p(n)-1}, T x_{p(n)-1}\right)+\gamma d\left(x_{q(n)-1}, T x_{q(n)-1}\right)\right. \\
+ & \left.\delta d\left(x_{p(n)-1}, T x_{q(n)-1}\right)+L d\left(T x_{p(n)-1}, x_{q(n)-1}\right)\right) \\
= & F\left(\alpha d\left(x_{p(n)-1}, x_{q(n)-1}\right)+\beta d\left(x_{p(n)-1}, x_{p(n)}\right)+\gamma d\left(x_{q(n)-1}, x_{q(n)}\right)\right. \\
+ & \left.\delta d\left(x_{p(n)-1}, x_{q(n)}\right)+L d\left(x_{p(n)}, x_{q(n)-1}\right)\right) \\
\leq & F\left(\alpha\left[d\left(x_{p(n)}, x_{q(n)}\right)+d_{p(n)-1}+d_{q(n)-1}\right]+\beta d_{p(n)-1}+\gamma d_{q(n)-1}\right. \\
+ & \left.\delta\left[d\left(x_{p(n)}, x_{q(n)}\right)+d_{p(n)-1}\right]+L\left[d\left(x_{p(n)}, x_{q(n)}\right)+d_{q(n)-1}\right]\right) \\
= & F\left((\alpha+\delta+L) d\left(x_{p(n)}, x_{q(n)}\right)+(\alpha+\beta+\delta) d_{p(n)-1}+(\alpha+\gamma+L) d_{q(n)-1}\right) \\
\leq & F\left(d\left(x_{p(n)}, x_{q(n)}\right)+d_{p(n)-1}+(\alpha+\gamma+L) d_{q(n)-1}\right) .
\end{aligned}
$$

Taking the limit as $n \rightarrow \infty$ in the above inequality, we get $\tau+F(\epsilon+0) \leq F(\epsilon+0)$, which is a contradiction. This shows that $\left\{x_{n}\right\}_{n \in \mathbb{N}}$ is a Cauchy sequence. Since $(X, d)$ is a complete metric space, we have that $\left\{x_{n}\right\}_{n \in \mathbb{N}}$ converges to some point $x^{*}$ in $X$.

If there exists a sequence $\{p(n)\}_{n \in \mathbb{N}}$ of natural numbers such that $x_{p(n)+1}=T x_{p(n)}=T x^{*}$, then $\lim _{n \rightarrow \infty} x_{p(n)+1}=x^{*}$, so $T x^{*}=x^{*}$. Otherwise, there exists $N \in \mathbb{N}$ such that $x_{n+1}=T x_{n} \neq$ $T x^{*}, \forall n \geq N$. Assume that $T x^{*} \neq x^{*}$. By the hypothesis, we have

$$
\begin{aligned}
& \tau+F\left(d\left(T x_{n}, T x^{*}\right)\right) \\
\leq & F\left(\alpha d\left(x_{n}, x^{*}\right)+\beta d\left(x_{n}, T x_{n}\right)+\gamma d\left(x^{*}, T x^{*}\right)+\delta d\left(x_{n}, T x^{*}\right)+L d\left(T x_{n}, x^{*}\right)\right),
\end{aligned}
$$

so

$$
\begin{aligned}
& \tau+F\left(d\left(T x_{n}, T x^{*}\right)\right) \\
= & F\left(\alpha d\left(x_{n}, x^{*}\right)+\beta d\left(x_{n}, x_{n+1}\right)+\gamma d\left(x^{*}, T x^{*}\right)+\delta d\left(x_{n}, T x^{*}\right)+L d\left(x_{n+1}, x^{*}\right)\right) .
\end{aligned}
$$

Since $F$ is increasing, we deduce that

$$
\begin{aligned}
& d\left(T x_{n}, T x^{*}\right) \\
< & \alpha d\left(x_{n}, x^{*}\right)+\beta d\left(x_{n}, x_{n+1}\right)+\gamma d\left(x^{*}, T x^{*}\right)+\delta d\left(x_{n}, T x^{*}\right)+L d\left(x_{n+1}, x^{*}\right),
\end{aligned}
$$

so letting $n$ tend to $\infty$, we get

$$
d\left(x^{*}, T x^{*}\right) \leq \gamma d\left(x^{*}, T x^{*}\right)+\delta d\left(x^{*}, T x^{*}\right)<d\left(x^{*}, T x^{*}\right) .
$$

This is a contradiction. Therefore, $T x^{*}=x^{*}$. Now, we will show that $T$ has a unique fixed point. Let $x, y \in X$ be two distinct fixed points of $T$. Thus $T x=x \neq y=T y$. Hence, $d(T x, T y)=d(x, y)>0$. By the hypothesis, since $0<\alpha+\delta+L \leq 1$, we have

$$
\begin{aligned}
& \tau+F(d(x, y)) \\
= & \tau+F(d(T x, T y)) \\
\leq & F(\alpha d(x, y)+\beta d(x, T x)+\gamma d(y, T y)+\delta d(x, T y)+L d(y, T x)) \\
= & F(\alpha d(x, y)+\delta d(x, y)+L d(x, y)) \\
\leq & F((\alpha+\delta+L) d(x, y) \\
\leq & F(d(x, y))
\end{aligned}
$$

This is a contradiction. Therefore, $T$ has a unique fixed point. 
As a first corollary of Theorem 5, taking $\alpha=1$ and $\beta=\gamma=\delta=L=0$, we obtain Theorem 2 of Wardowski. Furthermore, for $\delta=L=0$, we obtain a Reich [12] type theorem.

Corollary 1. Let $(X, d)$ be a complete metric space and let $T$ be a self-mapping on $X$. Assume that there exist $F: \mathbb{R}_{+} \rightarrow \mathbb{R}$ an increasing mapping and $\tau>0$ such that

$$
\tau+F(d(T x, T y)) \leq F(\alpha \cdot d(x, y)+\beta \cdot d(x, T x)+\gamma \cdot d(y, T y)),
$$

for all $x, y \in X, T x \neq T y$, where $\alpha+\beta+\gamma=1, \alpha>0$. Then $T$ has a unique fixed point in $X$.

Corollary 2. Let $(X, d)$ be a complete metric space and let $T$ be a self-mapping on $X$. Assume that there exist $F: \mathbb{R}_{+} \rightarrow \mathbb{R}$ an increasing mapping and $\tau>0$ such that

$$
\tau+F(d(T x, T y)) \leq F(d(x, y))
$$

for all $x, y \in X, T x \neq T y$. Then $T$ has a unique fixed point in $X$.

Example 1. Let $X=\left\{A_{n}: n \in \mathbb{N}\right\} \cup\{B\}$ and $d: X \times X \rightarrow[0, \infty)$ such that $d\left(A_{n}, A_{n}\right)=d(B, B)=0$ for every $n, d\left(A_{n}, A_{n+p}\right)=d\left(A_{n+p}, A_{n}\right)=d\left(A_{n}, B\right)=d\left(B, A_{n}\right)=\frac{1}{n}$ for all $n, p \in \mathbb{N}$.

Obviously $(X, d)$ is a complete metric space.

Let $T: X \rightarrow X$ such that $T A_{n}=A_{n+1}$ and $T B=B$.

Let us suppose that there exist $F: \mathbb{R}_{+} \rightarrow \mathbb{R}$ satisfying the hypothesis of Theorem 2. Taking $x=A_{n+i}$, $y=A_{n+i+1}$, we have for every $n \geq 1$ and $i \geq 0$

$$
\tau+F\left(d\left(T A_{n+i}, T A_{n+i+1}\right)\right)=\tau+F\left(\frac{1}{n+i+1}\right) \leq F\left(\frac{1}{n+i}\right)
$$

We get

$$
\sum_{i=0}^{p-1}\left(\tau+F\left(\frac{1}{n+i+1}\right)\right) \leq \sum_{i=0}^{p-1} F\left(\frac{1}{n+i}\right), p \in \mathbb{N},
$$

by where

$$
p \tau+F\left(\frac{1}{n+p}\right) \leq F\left(\frac{1}{n}\right)
$$

hence

$$
\tau+\frac{1}{p} F\left(\frac{1}{n+p}\right) \leq \frac{1}{p} F\left(\frac{1}{n}\right) .
$$

Taking $p$ integer such that $p \leq n^{k}<p+1$, we get by (F3) $\lim _{n \rightarrow \infty} \frac{n^{k}}{p}=1$, so $\lim _{n \rightarrow \infty} \frac{1}{p} F\left(\frac{1}{n}\right)=\lim _{n \rightarrow \infty} \frac{n^{k}}{p}$. $\frac{1}{n^{k}} F\left(\frac{1}{n}\right)=0$ and $\lim _{n \rightarrow \infty} \frac{1}{p} F\left(\frac{1}{n+p}\right)=\lim _{n \rightarrow \infty} \frac{(n+p)^{k}}{n^{k}} \cdot \frac{n^{k}}{p} \cdot \frac{1}{(n+p)^{k}} F\left(\frac{1}{n+p}\right)=0$.

Therefore, taking the limit as $n \rightarrow \infty$ in Inequality (9) we obtain $\tau \leq 0$, a contradiction. Hence $F$ cannot satisfy the hypothesis of Theorem 2.

But $F: \mathbb{R}_{+} \rightarrow \mathbb{R}, F(x)=-\frac{1}{x}$ is increasing and satisfies Corollary 2:

$$
\begin{aligned}
\tau+F\left(d\left(T A_{n}, T A_{n+p}\right)\right)= & \tau+F\left(\frac{1}{n+1}\right)=\tau-n-1 \leq-n \\
= & F\left(\frac{1}{n}\right)=F\left(d\left(A_{n}, A_{n+p}\right)\right), \text { for } \tau \leq 1, \\
\tau+F\left(d\left(T A_{n}, T B\right)\right)= & \tau+F\left(\frac{1}{n+1}\right) \leq F\left(\frac{1}{n}\right) \\
& =F\left(d\left(A_{n}, B\right)\right), \text { for } \tau \leq 1 .
\end{aligned}
$$


Now, we will prove a new version of Theorem 2, which shows that the monotony of $F$ it is not a necessary condition.

Theorem 6. Let $T$ be a selfmapping of a complete metric space $X$ into itself. Suppose there exists $\tau>0$ such that

$$
\forall x, y \in X,[d(T x, T y)>0 \Rightarrow \tau+F(d(T x, T y)) \leq F(d(x, y))],
$$

where $F: \mathbb{R}_{+} \rightarrow \mathbb{R}$ is a mapping satisfying the conditions ( F2) and $\left(F 3^{\prime \prime}\right)$, where

$\left(F 3^{\prime \prime}\right) \quad F$ is continuous on $(0, \alpha)$, with $\alpha$ a positive real number.

Then, Thas a unique fixed point $x^{*} \in X$ and for every $x \in X$ the sequence $\left\{T^{n} x\right\}_{n \in \mathbb{N}}$ converges to $x^{*}$.

Proof. The proof is similar to the proof of Theorem 2.1 in the paper [18]. Choose $x_{0} \in X$ and construct a sequence $\left\{x_{n}\right\}_{n \in \mathbb{N}} \in X$ by

$$
x_{1}=T x_{0}, x_{2}=T x_{1}=T^{2} x_{0}, \ldots, x_{n}=T x_{n-1}=T^{n} x_{0}, \forall n \in \mathbb{N} .
$$

If there exists $n \in \mathbb{N} \cup\{0\}$ such that $d\left(x_{n}, T x_{n}\right)=0$, then $x_{n}$ is a fixed point of $T$ and the proof is complete. Hence, we assume that

$$
0<d\left(x_{n}, T x_{n}\right)=d\left(T x_{n-1}, T x_{n}\right), \forall n \in \mathbb{N}
$$

By the hypothesis we have

$$
\tau+F\left(d\left(T x_{n-1}, T x_{n}\right)\right) \leq F\left(d\left(x_{n-1}, x_{n}\right)\right), \forall n \in \mathbb{N},
$$

i.e.,

$$
\begin{aligned}
F\left(d\left(T x_{n-1}, T x_{n}\right)\right) & \leq F\left(d\left(x_{n-1}, x_{n}\right)\right)-\tau=F\left(d\left(T x_{n-2}, T x_{n-1}\right)\right)-\tau \\
& \leq F\left(d\left(x_{n-2}, x_{n-1}\right)\right)-2 \tau=F\left(d\left(T x_{n-3}, T x_{n-2}\right)\right)-2 \tau \\
& \leq F\left(d\left(x_{n-3}, x_{n-2}\right)\right)-3 \tau=F\left(d\left(T x_{n-4}, T x_{n-3}\right)\right)-3 \tau \\
& \leq \cdots \\
& \leq F\left(d\left(x_{0}, x_{1}\right)\right)-n \tau .
\end{aligned}
$$

This implies that

$$
\lim _{n \rightarrow \infty} F\left(d\left(x_{n}, x_{n+1}\right)\right)=\lim _{n \rightarrow \infty} F\left(d\left(T x_{n-1}, T x_{n}\right)\right)=-\infty
$$

By (F2) we obtain that

$$
\lim _{n \rightarrow \infty} d\left(x_{n}, x_{n+1}\right)=0 .
$$

Now, we claim that $\left\{x_{n}\right\}_{n \in \mathbb{N}}$ is a Cauchy sequence. Arguing by contradiction, we assume that there exists $0<\epsilon<\alpha$ and sequences $\{p(n)\}_{n \in \mathbb{N}}$ and $\{q(n)\}_{n \in \mathbb{N}}$ of natural numbers such that

$$
p(n)>q(n)>n, d\left(x_{p(n)}, x_{q(n)}\right) \geq \epsilon, d\left(x_{p(n)-1}, x_{q(n)}\right)<\epsilon, \forall n \in \mathbb{N} .
$$

Like in the proof of Theorem 5, we obtain

$$
\lim _{n \rightarrow \infty} d\left(x_{p(n)}, x_{q(n)}\right)=\lim _{n \rightarrow \infty} d\left(x_{p(n)-1}, x_{q(n)-1}\right)=\epsilon .
$$

By the hypothesis, we have

$$
\tau+F\left(d\left(T x_{p(n)-1}, T x_{q(n)-1}\right)\right) \leq F\left(d\left(x_{p(n)-1}, x_{q(n)-1}\right)\right), \forall n \in \mathbb{N} .
$$


This implies

$$
\tau+F\left(d\left(x_{p(n)}, x_{q(n)}\right)\right) \leq F\left(d\left(x_{p(n)-1}, x_{q(n)-1}\right)\right), \forall n \in \mathbb{N} .
$$

By $\left(F 3^{\prime \prime}\right)$, taking the limit as $n \rightarrow \infty$, we get $\tau+F(\epsilon) \leq F(\epsilon)$, which is a contradiction. Therefore, $\left\{x_{n}\right\}_{n \in \mathbb{N}}$ is a Cauchy sequence. By completeness of $(X, d)$, it follows that $\left\{x_{n}\right\}_{n \in \mathbb{N}}$ converges to some point $x^{*} \in X$.

Now, we claim that $x^{*}$ is a fixed point of $T$. Arguing by contradiction, we assume that $T x^{*} \neq x^{*}$. If there exists a sequence $\left\{p_{n}\right\}_{n \in \mathbb{N}}$ of natural numbers such that $x_{p(n)+1}=T x_{p(n)}=T x^{*}$, then $\lim _{n \rightarrow \infty} x_{p(n)+1}=x^{*}$, so $T x^{*}=x^{*}$. This is a contradiction. Hence, there exists $N \in \mathbb{N}$ such that $x_{n+1}=T x_{n} \neq T x^{*}, \forall n \geq N$. Then, by hypothesis, we get

$$
\tau+F\left(d\left(x_{n+1}, T x^{*}\right)\right) \leq F\left(d\left(x_{n}, x^{*}\right)\right), \forall n \geq N .
$$

By $\left(F 3^{\prime \prime}\right)$, taking the limit as $n \rightarrow \infty$ in the above inequality, we have $\lim _{n \rightarrow \infty} F\left(d\left(x_{n+1}, T x^{*}\right)\right)=-\infty$. Hence, by $(F 2)$ we get $\lim _{n \rightarrow \infty} d\left(x_{n+1}, T x^{*}\right)=0$, which implies $d\left(x^{*}, T x^{*}\right)=0$. This is a contradiction. Therefore, $x^{*}$ is a fixed point of $T$. The uniqueness yields the same results as in the proof of Theorem 5 .

Example 2. Let $X=\{A, B, C, D, E\}$ and $d: X \times X \rightarrow[0, \infty)$ such that

$$
\begin{gathered}
d(M, M)=0, \text { for every } M \in X, \\
d(M, N)=d(N, M) \text { for every } M, N \in X, \\
d(A, B)=d(A, C)=d(A, D)=d(B, C)=d(B, D)=2, \\
d(A, E)=d(B, E)=d(C, D)=3, d(C, E)=d(D, E)=\frac{3}{2} .
\end{gathered}
$$

Obviously, $d$ is a metric on $X$ and $(X, d)$ is a complete metric space.

Let $T: X \rightarrow X$ such that $T A=C, T B=D, T C=T D=T E=E$.

Every $F: \mathbb{R}_{+} \rightarrow \mathbb{R}$ satisfying Relation (10) cannot be increasing because $F(d(T A, T B))=$ $F(d(C, D))=F(3), F(d(A, B))=F(2)$, so $F$ does not verify $(F 1)$.

Let $F: \mathbb{R}_{+} \rightarrow \mathbb{R}$,

$$
F(x)=\left\{\begin{array}{cc}
-\frac{1}{x}, & x \in\left(0, \frac{3}{2}\right] \\
x-\frac{13}{6}, & x \in\left(\frac{3}{2}, \frac{5}{2}\right] \\
\frac{-4 x+11}{3}, & x \in\left(\frac{5}{2}, 5\right] \\
x-8, & x \in(5, \infty)
\end{array}\right.
$$

It is easy to prove that $F$ satisfy $\left(F 3^{\prime \prime}\right)$ and $(F 2)$.

For $x=A, y=C$ or $x=A, y=D$ or $x=B, y=C$ or $x=B, y=D$ we have $F(d(T x, T y))=$ $F\left(\frac{3}{2}\right)=-\frac{2}{3}$ and $F(d(x, y))=F(2)=-\frac{1}{6}$ so we have $\tau-\frac{2}{3} \leq-\frac{1}{6}$ or $\tau \leq \frac{1}{2}$.

For $x=A, y=E$ or $x=B, y=E$ we get $F(d(T x, T y))=F\left(\frac{3}{2}\right)=-\frac{2}{3}$ and $F(d(x, y))=F(3)=$ $-\frac{1}{3}$ so we have $\tau-\frac{2}{3} \leq-\frac{1}{3}$ or $\tau \leq \frac{1}{3}$.

Hence we can choose $\tau=\frac{1}{6}$. Therefore, F satisfies the hypothesis of Theorem 6, but does not verify Theorem 2.

\section{Conclusions}

In this paper, we generalize some results of Wardowski (Fixed Point Theory Appl. 2012:94, 2012), Cosentino and Vetro (Filomat 28:4, 2014), and Piri and Kumam (Fixed Point Theory Appl. 2014:210, 2014) theorems by applying some weaker conditions on the self map of a complete metric space and on the mapping F, concerning the contractions defined by Wardowski. Furthermore, we presented some examples to support our main results. 
Author Contributions: Conceptualization, O.P. and G.S.; methodology, O.P. and G.S.; investigation, O.P. and G.S.; writing-original draft preparation, O.P. and G.S.; writing—review and editing, O.P. and G.S. All authors have read and agreed to the published version of the manuscript.

Funding: The author declares that there is no funding for the present paper.

Conflicts of Interest: The authors declare no conflict of interest.

\section{References}

1. Banach, S. Sur les opérationes dans les ensembles abstraits et leur application aux équation intégrales. Fund. Math. 1922, 3, 133-181. [CrossRef]

2. Caristi, J. Fixed point theorems for mappings satisfying inwardness conditions. Trans. Am. Math. Soc. 1976, 215, 241-251. [CrossRef]

3. Caristi, J.; Kirk, W.A. Geometric fixed point theory and inwardness conditions. In The Geometry of Metric and Linear Spaces; Lecture Notes in Mathematics; Springer: Berlin/Heidelberg, Germany, 1975; Volume 490, pp. 74-83.

4. Chatterjea, S.K. Fixed-point theorems. Comtes Rendus L'Acad. Bulg. Sci. 1972, 25, 727-730. [CrossRef]

5. Ćirić, L.B. A generalization of Banach's contraction principle. Proc. Am. Math. Soc. 1974, 45, $267-273$. [CrossRef]

6. Ćirić, L.B. A new fixed-point theorem for contractive mappings. Publ. Inst. Math. 1981, 30, $25-27$.

7. Dugundji, J. Positive definite functions and coincidences. Fund. Math. 1976, 90, 131-142. [CrossRef]

8. Ekeland, I. On the variational principle. J. Math. Anal. Appl. 1974, 47, 324-353. [CrossRef]

9. Geraghty, M. On contractive mappings. Proc. Am. Math. Soc. 1973, 40, 604-608. [CrossRef]

10. Kannan, R. Some results on fixed points. Bull. Calcutta Math. Soc. 1968, 60, 71-76.

11. Nadler, S.B., Jr. Multi-valued contraction mappings. Pac. J. Math. 1969, 30, 475-488. [CrossRef]

12. Reich, S. Some remarks concerning contraction mappings. Can. Math. Bull. 1971, 14, 121-124. [CrossRef]

13. Rhoades, B.E. A comparison of various definitions of contractive mappings. Trans. Am. Math. Soc. 1977, 226, 257-290. [CrossRef]

14. Edelstein, M. On fixed and periodic points under contractive mappings. J. Lond. Math. Soc. 1962, 37, 74-79. [CrossRef]

15. Wardowski, D. Fixed points of a new type of contractive mappings in complete metric space. Fixed Point Theory Appl. 2012, 2012, 94. [CrossRef]

16. Secelean, N.A. Iterated function system consisting of F-contarctions. Fixed Point Theory Appl. 2013, $2013,277$. [CrossRef]

17. Cosentino, V.; Vetro, P. Fixed Point Result for F-contractive Mappings of Hardy-Rogers-Type. Filomat 2014, 28, 715-722. [CrossRef]

18. Piri, H.; Kumam, P. Some fixed point theorems concerning F-contraction in complete metic spaces. Fixed Point Theory Appl. 2014, 2014, 210. [CrossRef]

19. Abbas, M.; Ali, B.; Romaguera, S. Fixed and periodic points of generalized contractions in metric spaces. Fixed Point Theory Appl. 2013, 243. [CrossRef]

20. Abbas, M.; Ali, B.; Romaguera, S. Generalized Contractions and Invariant Approximation Results on Nonconvex Subsets of Normed Spaces. Abstr. Appl. Anal. 2014, 2014, 391952. [CrossRef]

21. Acar, O.; Altun, I. A fixed point theorem for multivalued mappings with $\delta$-distance. Abstr. Appl. Anal. 2014, 2014, 497092. [CrossRef]

22. Altun, I.; Olgun, M.; Minak, G. On a new class of multivalued weakly Picard operators in complete metric spaces. Taiwan. J. Math. 2015, 19, 659-672. [CrossRef]

23. Batra, R.; Vashishta, S. Fixed point theorem for Fw-contractions in complete metric spaces. J. Nonlin. Anal. Appl. 2013, 2013, 211. [CrossRef]

24. Batra, R.; Vashishta, S.; Kumar, R. Coincidence Point Theorem for a New Type of Contraction on Metric Spaces. Int. J. Math. Anal. 2014, 8, 1315-1320. [CrossRef]

25. Batra, R.; Vashishta, S. Fixed points of an F-contraction on metric spaces with a graph. Int. J. Comp. Math. 2014, 91, 2483-2490. [CrossRef]

26. Gupta, A. Fixed points of a new type of contractive mappings in G-metric spaces. Int. J. Adv. Math. 2014, $1,56-61$. 
27. Hussain, N.; Salimi, P. Suzuki-Wardowski type fixed point theorems for $\alpha$-GF-contractions. Taiwan. J. Math. 2014. [CrossRef]

28. Malhatra, S.K.; Radenovic, S.; Shukla, S. Some fixed point results without monotone property in partially ordered metric-like space. J. Egyptian Math. Soc. 2014, 22, 83-89. [CrossRef]

29. Paesano, D.; Vetro, C. Multi-valued F-contractions in $O$-complete partial metric spaces with application to Volterra type integral equation. RACSAM 2014, 108, 1005-1020. [CrossRef]

30. Sgroi, M.; Vetro, C. Multi-valued F-contraction and the solutions of certain functional and integral equations. Filomat 2013, 27, 1259-1268. [CrossRef]

31. Shukla, S.; Radenovic, S.; Kadelburg, Z. Some Fixed Point Theorems for Ordered F-Generalized Contractions in O-f-orbitally Complete Partial Metric Spaces. Theory Appl. Math. Comput. Sci. 2014, 4, 87-98.

(C) 2019 by the authors. Licensee MDPI, Basel, Switzerland. This article is an open access article distributed under the terms and conditions of the Creative Commons Attribution (CC BY) license (http:/ / creativecommons.org/licenses/by/4.0/). 